\title{
Assessing the Economic Benefits of Compressed Air Energy Storage for Mitigating Wind Curtailment
}

\author{
Brendan Cleary \\ Technological University Dublin, brendan.cleary1@mydit.ie \\ Aidan Duffy \\ Technological University Dublin, aidan.duffy@tudublin.ie \\ Alan O'Connor \\ Trinity College, alan.oconnor@tcd.ie
}

See next page for additional authors

Follow this and additional works at: https://arrow.tudublin.ie/dubencon

Part of the Other Engineering Commons

\section{Recommended Citation \\ Cleary, B.; Duffy, A.; O Connor, A.; Conlon, M.; Fthenakis, V.,(2015), "Assessing the Economic Benefits of Compressed Air Energy Storage for Mitigating Wind Curtailment," Sustainable Energy, IEEE Transactions on, vol.PP, no.99, pp.1,8 doi: 10.1109/TSTE.2014.2376698}

This Other is brought to you for free and open access by the Dublin Energy Lab at ARROW@TU Dublin. It has been accepted for inclusion in Other resources by an authorized administrator of ARROW@TU Dublin. For more information, please contact arrow.admin@tudublin.ie, aisling.coyne@tudublin.ie,gerard.connolly@tudublin.ie. Funder: Part funded by Technological University Dublin and Fulbright Commission of Ireland

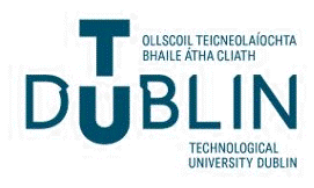




\section{Authors}

Brendan Cleary, Aidan Duffy, Alan O'Connor, Michael Conlon, and Vasilis Fthenakis

This other is available at ARROW@TU Dublin: https://arrow.tudublin.ie/dubencon/3 


\section{Assessing the Economic Benefits of Compressed Air Energy Storage for Mitigating Wind Curtailment}

5 Abstract-Renewable energy generation in the All-Island of 6 Ireland (AII) is set to increase by 2020 due to binding renewable energy targets. To achieve these targets, there will be periods 8 of time when $75 \%$ of electricity will be generated mainly from onshore wind. Currently, the AII system can accommodate a 50\% 0 maximum permissible instantaneous level of wind generation. The 1 system operators must make system-wide wind curtailment deci2 sions to ensure that this level is not breached. Subsequently, the 3 ability to limit wind curtailment using large-scale energy storage 4 such as pumped hydroelectric energy storage and compressed air 5 energy storage (CAES) is increasingly being scrutinized as a viable 16 option. Thus, the aims of this paper are to estimate the level of 7 wind curtailment on the 2020 AII system for various scenarios 8 including with and without CAES, and assess and quantify the rev9 enue loss due to wind curtailment using power systems simulation software PLEXOS.

Index Terms-Compressed air energy storage (CAES), energy markets, PLEXOS, power system economics, power system modeling, power system operation, revenue, total generation costs, wind curtailment, wind power.

AII
CAES
MSQ
RES
SMP
SNSP

NOMENCLATURE
All-Island of Ireland.
Compressed air energy storage.
Market schedule quantities.
Renewable energy sources.
System marginal prices.
System nonsynchronous penetration.

\section{NOMENCLATURE}

\section{(nt}

in Portugal, and $14.5 \%$ in Ireland [1]. This higher provision in European countries is driven by the European Commission's framework that put in place in 2009, built around 2020 targets for renewable energy $(20 \%)$, greenhouse gas emission reduction (20\%), and energy efficiency (20\%) [2].

In particular, the governments of the Republic of Ireland (ROI) and Northern Ireland (NI) have set an ambitious target that requires $40 \%$ of electricity to come from RES, predominately wind, by 2020 [3]. The current and proposed 2020 level of installed wind capacity across the $\mathrm{AII}^{1}$ is, and will continue to be, one of the highest global levels relative to the size of the system [4]. The transmission system operators (TSOs) Eirgrid and SONI are seeking to operate between 5000 and $6000 \mathrm{MW}$ of wind capacity across the AII by 2020 [5]. This represents circa $37 \%-41 \%$ of the total generation capacity in 2020 .

The increasing amount of wind capacity due for connection introduces a new challenge for the TSOs in maintaining the stability of the system. Currently, the AII system can accommodate a $50 \%$ maximum permissible instantaneous level of nonsynchronous generation such as wind. As a consequence, the TSOs must make system-wide curtailment decisions, particularly in the case of wind generation to ensure that this level is not breached.

Since 2003, curtailment has been highlighted by the Irish wind energy sector as a potential limiting factor to the longterm growth of wind farm development in Ireland. In the meantime, policy makers have taken limited action to effectively address this issue and enact mitigating measures. In 2011, curtailment levels for all wind farms across the AII averaged $2 \%$ with some wind farms experiencing no curtailment while others had levels of $7 \%-8 \%$ [6]. It should be noted, however, that during this year, outages on the Moyle interconnector (MI) between NI and Scotland and the only pumped storage plant in the AII resulted in higher levels of curtailment than would otherwise have been expected [7].

More recently, the Single Electricity Market (SEM) Committee for the AII has been considering matters associated with curtailment in tie-break situations. The committee decided that operational wind farms (both firm and nonfirm) will be turned down on an equal basis in a curtailment situation from March 1, 2013. Furthermore, compensation payments for curtailment will cease on the January 1, 2018, and the TSOs and SEM operator will be responsible for implementing this through the relevant grid code and market structure, respectively [8].

\footnotetext{
${ }^{1}$ The ROI and NI are two separate jurisdictions with a common synchronous power system known as the All-Island of Ireland (AII).
}

V. Fthenakis is with the Center for Life Cycle Analysis, Columbia University, New York, NY 10027 USA (e-mail: vmf5@ columbia.edu).

Digital Object Identifier 10.1109/TSTE.2014.2376698 
Subsequently, the decision to remove compensation for curtailment by 2018 will be of major concern to investors in the wind energy sector. It is, therefore, essential that ongoing work including: Eirgrid's DS3 and Grid 25 programs are delivered on time in order to minimize the occurrences of curtailment. These programs involve developing financial incentives for enhanced plant performance, operational policies, system tools, and additional grid infrastructure development.

Large-scale energy storage such as pumped hydroelectric energy storage (PHES) and CAES also allows curtailed wind energy to be stored until it is required [9]. Currently, only one 292 MW PHES plant exists in the AII and has been operational since 1974. However, despite PHES being considered a mature technology, further development in the AII has ceased mainly due to the lack of suitable sites, high initial capital costs, and environmental impact concerns.

Apart from PHES, CAES is the only commercial large-scale storage technology to have been deployed at utility scale, and a number of research projects have analyzed CAES as a solution to improving wind integration and reducing wind curtailment [10]-[12]. An appraisal of the geological conditions and the potential of underground gas storage and CAES deployment were undertaken in Larne, NI [13]. Results indicated that Larne is the only place in NI and one of the few places in the AII, which has salt deposits potentially suitable for CAES [13], [14]. Hence, the potential exists for a 268-MW CAES plant to be connected to the AII system [14].

In summary, CAES can reduce wind curtailment and improve the long-term growth of wind farm development in the AII. Thus, the aims of the paper are 1) to estimate the level of wind curtailment on the 2020 AII system for various scenarios including with and without CAES and 2) to assess and quantify the revenue loss to wind generation due to the termination of wind curtailment compensation.

\section{Compressed Air Energy Storage}

\section{A. Overview of Technology}

CAES is a hybrid form of storage and is a modification of the conventional gas turbine (GT) technology. A CAES plant consists of a power train motor used to drive a compressor to compress air into a reservoir, a high- and low-pressure turbine, and a generator. The reservoir is either an aboveground vessel/pipe or an underground geologic formation such as salt, rock, and saline aquifers.

A CAES plant operates similarly to a conventional GT with the compression and expansion stages occurring independently or concurrently depending on the plant type. During the compression stage, excess electricity or off peak low cost electricity is used to run a chain of compressors which injects air into the reservoir.

During the expansion stage, when electricity is required, pressurized air is released from the reservoir and used to run a turbine which produces electricity. In order to improve the power output of the turbine, natural gas is used in the combustion cycle. This allows electricity to be generated using 135 only $33 \%$ of the natural gas required to generate the same 136 $\begin{array}{ll}\text { amount of electricity as a conventional GT [15]. } & 137\end{array}$

CAES plant designs are categorized based on the method 138 of managing heat from compression and expansion of the air. 139 These categories are diabatic, adiabatic, and isothermal. In 140 diabatic CAES (often referred to as "conventional" or "first 141 generation" CAES), the heat of compression is removed and 142 dissipated during compression and the air is reheated during 143 expansion [16]. Second-generation CAES is similar to first gen- 144 eration except a modified design that leads to improved com- 145 pression and/or expansion stages using air injection techniques 146 to increase efficiency.

In adiabatic CAES (referred to as "third-generation" CAES), 148 the heat of compression is stored in a solid or fluid and returned 149 to the air during expansion [16]. Therefore, no natural gas is 150 required to heat the compressed air in the combustion cham- 151 ber. Similarly, in an advanced adiabatic (AA) CAES plant, 152 the waste heat is captured and rereleased into the compressed 153 air, so that no gas co-combustion to heat the compressed air 154 is required. The key benefits of adiabatic and AA CAES are 155 higher efficiencies and reduced carbon emissions as there is no 156 fuel consumption required during generation.

In Isothermal CAES, the compression and expansion stages 158 are conducted in a slow manner to ensure that the air is main- 159 tained at an approximate constant temperature through heat 160 exchanges with the environment [16]. The theoretical efficiency 161 of isothermal CAES approaches $100 \%$ for perfect heat transfer 162 to the environment. However, in practice, perfect thermody- 163 namic cycles are not obtainable as some heat loss occurs. In 164 conclusion, both AA and isothermal CAES are still at the 165 research and development stage and it could be sometime 166 before large-scale deployment occurs.

\section{B. Review of Developments}

CAES is more than 40 years old, dating from the 1970s when 169 it was first deployed as a means of providing energy during 170 peak demand and bridging supply shortfalls from slow ramping 171 base load plants [17]. At present, there are two first-generation 172 diabatic CAES plants in operation, one in Huntorf, Germany 173 where a 290-MW plant was constructed in 1978 and another in 174 Alabama, USA where a 110-MW plant was constructed in 1991175 [10]. They were mainly built for their black start capabilities 176 and peak shaving services.

Some pilot CAES plants have been built in Japan and Italy 178 (25 MW) and are proposed for Israel and Russia. In the United 179 States (U.S.), construction of a diabatic 317-MW CAES plant 180 near Tennessee Colony, Texas is due to commence in Spring 181 2015 [18]. Moreover, it will be the first CAES plant to be built 182 in the U.S. since the plant in Alabama.

In Europe, the idea of developing CAES is obtaining momen- 184 tum due to the deployment of intermittent wind and solar power 185 plants. In particular, the TSOs in the ROI and NI are in dis- 186 cussion with an energy company about the connection of the 187 proposed 268 MW CAES plant in the Larne area, NI [19]. This 188 plant has been listed as a one of the projects of community 189 
interest within the European Union and is envisaged to be listed as critical infrastructure under the SEM [20].

The European Commission has supported the first AA CAES plant due for construction in Germany by 2016, entitled the "ADELE" project [21]. The aim of this project is to further advance the necessary components for this technology and to develop the basic concept for the first AA CAES plant.

The world's first 1.5 MW Isothermal CAES plant is located at SustainX headquarters in Seabrook, New Hampshire, USA [22]. The process involves capturing the heat produced during compression, trapping it in water, and storing the warmed air-water mixture in pipes. When electricity is required by the grid, the isothermal expansion delivers electricity with no requirement for natural gas combustion.

\section{Methodology}

\section{A. Modeling Software}

The main proprietary modeling software used in different countries for power systems modeling include EMCAS, PLEXOS, EnergyPLAN, WASP IV, and WILMAR [23]. The most common modeling software used for AII system modeling are WILMAR and PLEXOS. The WILMAR planning tool was first issued in 2006 and was originally used to study wind variability in the Nord pool system. It was then modified to analyze the Irish system as part of the All-Island Grid Study [24].

PLEXOS is an integrated energy software tool developed by Energy Exemplar and is used for power and gas market modeling worldwide [25]. Since 2007, PLEXOS has been used in Ireland by the TSOs, Commission for Energy Regulation (CER), and SEM participants to validate and forecast SEM outcomes [26], [27]. Moreover, it is considered by academia as a well-proved tool for policy analysis and development in the AII [11], [28]-[31]. Therefore, PLEXOS version 6.208 R04 was used to build and run the models for the analysis presented in this paper.

\section{B. Base Model Verification and Validation}

The CER provides publically accessible calibrated backcast and validated forecast PLEXOS models annually [27]. The CER uses these models to monitor gaming by simulating the SMP and market outcomes in the SEM.

In this study, the CER 2010 backcast model is used to replicate the actual ex-post SMP and MSQ observed in the SEM. The PLEXOS modeling configuration, which provided the best replication of the ex-post data across the simulation horizon, was then used to inform any recommendations for the 2011-2012 validated forecast model.

The CER 2010 backcast model was run for 365 days at $30 \mathrm{~min}$ intraday trading periods. The technical and commercial characteristics for each generator participating in the SEM were defined by submitted technical and commercial offer data [27]. This consists mainly of no load costs, start costs and start cost times, actual availabilities, min up/down times, and minimum stable level (MSL). This represented the exact data submitted by the generators to the SEM operator, which was verified by the CER.
A comparative validation analysis was conducted between 244 the backcast model outputs and the actual market outputs. The 245 mean absolute percentage errors (MAPE) were 6.1\% and 7.7\% 246 for average daily SMP and annual MSQ, respectively. The 247 backcast model produces a profile for the average daily SMP, 248 which is consistent with the actual market. It was noticeable 249 that there were regular price spikes and dips for the on-peak and 250 off-peak hours, respectively. Also, it generally produces higher 251 off-peak SMP than the actual market, whereas on-peak prices 252 are lower than observed in the actual market.

The discrepancies between the SMP and the MSQs can be 254 attributed to PLEXOS's tendency to over-schedule generators, 255 which reduces the shadow price but increases the uplift by a 256 similar amount. The shadow price makes up most of the SMP 257 and relates to the incremental short run marginal cost bids 258 from generators comprising of fuel and carbon costs. The uplift 259 component covers the generator's start-up and no-load costs. 260 Therefore, there are some instances where higher uplift was 261 caused by the cost recovery method in PLEXOS for generators 262 that only ever ran at MSL during the year. This effect was also 263 observed in previous validation studies, and it is recommended 264 that MSL and ramp rate uplift filters be kept on [27] and [32].

\section{2020 Model Description}

The CER-validated forecast model of 2011-2012 was used 267 as a starting point from which the 2020 model for this analysis 268 was developed. The 2020 model was populated with the indi- 269 vidual generator techno-economic parameters for new entrants 270 and retirements, which have signed agreements and confirmed 271 dates to connect to the AII system over the next 10 years [5]. 272 Similarly, the system demand and wind capacity for 2020 were 273 obtained from Eirgrid and SONI [5]. A simplified Great Britain 274 (GB) system and interconnections to the ROI and NI were 275 created in the model as per the validated forecast model [27]. 276

A main constraint restricting the amount of nonsynchronous 277 generation, mainly wind, on the AII system is enforced in the 278 model. This is known as the SNSP limit and is a measure of 279 the nonsynchronous generation on the AII system at an instant 280 in time as shown by (1) [33]. Based on extensive research by 281 the TSOs on high wind penetration levels, an SNSP limit was 282 identified as an all-encompassing indicator for the operational 283 ranges allowing secure operation of the AII system [33] 284

$$
\frac{\text { Wind generation }+ \text { imports }}{\text { System demand }+ \text { exports }} \leq \text { SNSP }
$$

where the SNSP limit ensures that the amount of wind gen- 285 eration, when added to interconnector imports, does not exceed 286 the sum of system demand and interconnector exports. The sys- 287 tem demand includes the pump storage and CAES consumption 288 when in pumping mode.

The PLEXOS simulation engine reads the input data such 290 as system demand and wind data as shown in Fig. 1. It simu- 291 lates 366 individual daily optimizations at half-hourly intervals 292 ensuring that the generation portfolio meets demand at least 293 cost while taking into account the generator's techno-economic 294 parameters. Generator and system-wide constraints are also 295 enforced for each simulation period. Similar to the SEM, the 296 


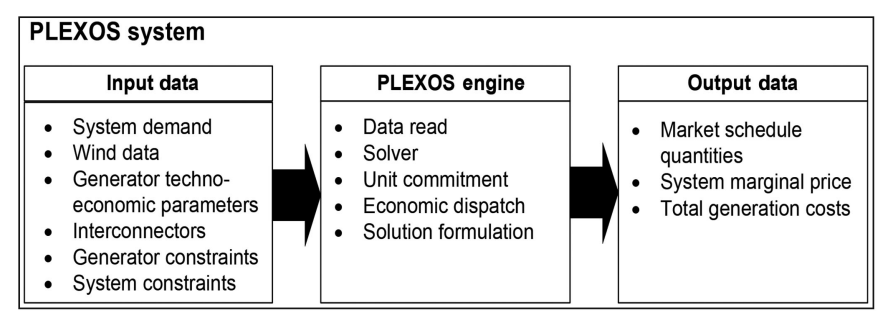

F1:1 Fig. 1. PLEXOS system modeling structure.

$\mathrm{T} 1: 1$ $\mathrm{T} 1: 2$
TABLE I

SCENARIo DEFINITIONS

\begin{tabular}{|c|c|c|}
\hline Scenarios & SNSP (\%) & $\begin{array}{c}\text { Wind } \\
\text { capacity } \\
\text { (MW) }\end{array}$ \\
\hline BAU & 50 & 3600 \\
\hline EOC & 75 & 5211 \\
\hline BAU+CAES & 50 & 3600 \\
\hline EOC+CAES & 75 & 5211 \\
\hline
\end{tabular}

solver calculates SMP and MSQ for each period; therefore, providing an accurate representation of the dispatch of generators in the AII system.

\section{Model Scenarios}

Table I shows the scenarios simulated in this analysis. Two main operational scenarios: 1) business as usual (BAU) and 2) enhanced operational capability (EOC) have been considered with the remaining two scenarios containing a CAES plant as an additional generator.

A description of each scenario is as follows.

1) BAU represents the current operational network constraints with a 50\% SNSP limit and an installed wind capacity of $3600 \mathrm{MW}$. The interconnector flows are set as a fixed input based on the outputs from a market unconstrained model run for this analysis. This approach replicates the current SEM rules, whereby interconnector nominations are determined by the ex-ante market dispatch schedule. Operating reserve requirements are assigned to each generator based on current operational policy. Hence, this scenario is considered to represent a realistic real time operation of the system.

2) EOC is the BAU scenario with a $75 \%$ SNSP limit instead of $50 \%$ and an installed wind capacity of $5211 \mathrm{MW}$ was assumed to achieve the required $37 \%$ of electricity from wind by 2020. It represents the possible operational network constraints if enhanced system services are implemented by 2020.

3) $\mathrm{BAU}+\mathrm{CAES}$ is the BAU scenario with a CAES plant included in the AII generation portfolio. The CAES plant only contributes to energy requirements in this scenario.
TABLE II

Generation CAPACITy PortFolio
${ }^{2} \mathrm{BAU}$ and BAU+CAES scenarios.

${ }^{3} \mathrm{EOC}$ and $\mathrm{EOC}+\mathrm{CAES}$ scenarios.

4) EOC + CAES is the EOC scenario with a CAES plant 328 included in the AII generation portfolio. In this sce- 329 nario, the CAES plant contributes to energy and operat- 330 ing reserve requirements, which are explained in more 331 detailed in Sections III-E and III-F.

\section{E. Main Model Assumptions}

The AII system demand is expected to increase $12 \%$ between 334 2011 and 2020 based on the median demand forecast by Eirgrid 335 [5]. The median demand forecast is considered to reflect the lat- 336 est projections for the AII based on the future economic climate 337 and has been used for several AII case studies. The annual sys- 338 tem median demand is estimated to be 41.2 TWh with a peak 339 demand of $7.3 \mathrm{GW}$. Accordingly, the 2011 demand time series 340 profile is linearly scaled to reflect the 2020 median demand 341 forecast.

A breakdown of the generator types used for the scenarios 343 simulated in this analysis is shown in Table II.

Onshore wind capacity varies for each scenario and it is 345 assumed that no more offshore wind will be developed in 346 the AII prior to 2020. It is assumed that only $25 \mathrm{MW}$ of 347 installed offshore wind capacity exists from a single wind farm 348 at Arklow Bank, Co., Wicklow, Ireland. 349

Wind generation is modeled under the assumption of perfect 350 foresight in aggregated form, split into 13 regions. The capacity 351 for each region is based on the proposed regional distribution of 352 renewable capacity by Eirgrid [34]. Each region has an associ- 353 ated half-hourly profile, which represents the wind availability 354 in that region in each half hour as a percentage of total installed 355 capacity in that region. These profiles were developed from 356 historical time series data from 2011. 
The general approach is to model wind generation with zero short run marginal costs (fuel, carbon, and start costs equal zero) based on the assumption that it will always run when available, due to its priority dispatch status. Similarly, predictable price takers peat, wave, waste, and CHP generators are assigned zero short run marginal cost to ensure that they are dispatched fully when available.

Modeling the GB system is required in order to determine the interconnector flows between SEM and GB. Gas generation has been the predominant marginal plant type on the GB system and a high correlation between the cost of gas generation and the GB electricity price has been determined [27]. A single gas generator of $2000 \mathrm{MW}$ with multiband heat rates, variable operating and maintenance (VOM) costs, and $1100 \mathrm{MW}$ of load was, therefore, used to represent the GB system.

The CER also adopts this simplified GB representation to determine SEM outcomes. GB wind is not modeled and significant data collection is required to create a complete GB system. Moreover, including the complete GB system in each scenario would significantly increase the computational time and so the approach described is applied.

The complete transmission network is not included in the model and localized network constraints are not modeled. Instead, the model consists of system-wide constraints and three separate nodes representing the ROI, NI, and GB systems. It is assumed that adequate transmission capacity as per Eirgrid's Grid 25 program has been built by 2020 to accommodate increased levels of wind capacity on the system.

There is a restricted flow of $450 \mathrm{MW}$ in the NI-ROI and 400 MW ROI-NI directions at present due to system security issues. However, the full rating of the north-south transmission line between NI and ROI is assumed to be in place by 2020 ; therefore, flows of $1500 \mathrm{MW}$ both ways are set within the model [35].

The MI links NI to Scotland, and flows on the MI are largely driven by arbitrage of the relative prices in the two systems. The MI is limited to exporting $300 \mathrm{MW}$ and importing $450 \mathrm{MW}$ November-March and 410 MW April-October. However, there is uncertainty in relation to the actual maximum import and export capacity of the MI for the foreseeable future due to an undersea cable fault [19]. The east-west (EW) interconnector between the ROI and GB nodes, maximum flow was assumed $500 \mathrm{MW}$ both ways.

The model applies historic transmission loss adjustment factors to all generators to account for the possible losses within the AII system. Planned and unplanned maintenance for each generator during the year is considered. The former is assigned manually based on the 2011 schedule and the latter is modeled as a random event.

The number of high inertia generators required online for system stability is applied as per the 2013 Transmission Constraint Groups (TCGs) requirements [36]. There are also constraints applied on certain groups of generators and maximum export capacities within certain regions. Including these constraints within the model allows for a more realistic real time system operation.

The reserve requirements for 2020 are set based on modified TCGs requirements to take account of the increased amount of
TABLE III

OPERATING RESERVE REQUIREMENTS

\begin{tabular}{|l|c|c|}
\hline Category & $\begin{array}{c}\text { Requirement of } \\
\text { largest in-feed } \\
(\%)\end{array}$ & $\begin{array}{c}\text { Minimum } \\
\text { dynamic } \\
\text { requirement } \\
\text { (MW) }\end{array}$ \\
\hline POR & 75 & 165 \\
\hline SOR & 75 & 165 \\
\hline TOR1 & 100 & 165 \\
\hline TOR2 & 100 & 165 \\
\hline
\end{tabular}

wind generation on the AII system. Three categories of operat- 416 ing reserve were modeled: 1) primary operating reserve (POR), 417 2) secondary operating reserve (SOR), and 3) two classes of 418 tertiary operating reserve (TOR1 and TOR2). It is assumed that 419 the reserve categories will remain unchanged as a result of the 420 TSOs DS3 program to refine the system services products [26]. 421

For each reserve category, there is a total requirement and a 422 minimum dynamic requirement. The total requirement ranges 423 between $75 \%$ and $100 \%$ of the largest electricity in-feed 424 depending on the reserve category [36]. This was based on 425 an assumed largest in-feed of $500 \mathrm{MW}$, corresponding to the 426 largest generator on the AII system, which is the EW intercon- 427 nector. The minimum requirement for each reserve category is 428 fixed at $165 \mathrm{MW}$. The total requirement as a percentage of the 429 largest in-feed and minimum dynamic requirement is outlined 430 in Table III.

Certain generators are assigned reserve capacities for each 432 reserve category for the provision of dynamic reserve. Static 433 reserve provision of $35 \mathrm{MW}$ of interruptible load is assumed 434 to be provided from the PHES plant during pumping mode for 435 static reserve [37], [38]. The MI and EW interconnectors are 436 assumed to hold 75 and $50 \mathrm{MW}$ of static reserve, respectively. 437

In summary, this analysis employs a deterministic model 438 using a set of main assumptions based on published data. The 439 analysis assumes perfect foresight for wind generation and sys- 440 tem demand with no significant rules changes to the SEM or to 441 the broader market by 2020. The analysis, therefore, applies the 442 current SEM rules and assumes the current bidding principles 443 and methodology for calculating the various cost and revenue 444 streams remain unchanged.

F. Modeling of Storage

A simplified modeling approach for the PHES plant is 447 adopted for the market unconstrained model. PHES is modeled 448 as four separate units similar to hydro units, which are allowed 449 to run from a zero level up to maximum capacity. In the pump 450 mode, the units are also allowed to pump from a zero level up 451 to maximum pump capacity. During the simulations, PHES is 452 forced to refill to a predefined target by the end of each day. 453 This approach was used previously for PHES modeling in the 454 SEM [39].

However, the real-time operation of the PHES plant is rather 456 different. For all scenarios, the PHES has three distinct modes: 457 1) spin, 2) min, and 3) pump. In spin mode, each unit can 458 provide $5 \mathrm{MW}$ but no more than two units can be in spin mode 459 
TABLE IV

CAES Plant Technical Operating Details [41]

\begin{tabular}{|l|c|c|}
\hline \multicolumn{1}{|c|}{ Parameters } & Value & Units \\
\hline Maximum compression & 200 & MW \\
\hline Minimum compression & 60 & MW \\
\hline Ramp rate for compression & 40 & $\mathrm{MW} / \mathrm{min}$ \\
\hline Maximum generation & 270 & $\mathrm{MW}$ \\
\hline Minimum generation & 67.5 & $\mathrm{MW}$ \\
\hline Ramp rate for generation & 54 & $\mathrm{MW} / \mathrm{min}$ \\
\hline CAES heat rate & 4.265 & $\mathrm{GJ} / \mathrm{MWh}$ \\
\hline CAES storage capacity & 3 & $\mathrm{GWh}$ \\
\hline Compressing efficiency & 80 & $\%$ \\
\hline Part load energy ratio $\left(\mathrm{kWh}_{\text {in }} / \mathrm{kWh}_{\text {out }}\right)$ & 0.83 & \\
\hline
\end{tabular}

at any one time with the remaining two units providing a minimum generation level of $35 \mathrm{MW}$. In min mode, each unit can provide between 40 and $73 \mathrm{MW}$, which contributes to both POR and SOR. The PHES units share a common penstock; therefore, a constraint to prevent concurrent generation and pumping is set within the model. In the final mode, pump mode, the PHES four fixed speed pump units can each draw a load of 71.5 MW from the AII grid and can provide full capacity for POR. Again, these three operational modes were adopted previously for real-time PHES modeling in the AII system [30].

A CAES plant is represented within the model by a PHES plant coupled with a GT plant using constraints to replicate the operation of the CAES plant. In compression mode, the PHES plant draws power from the grid to compress air; whereas, in generation mode, both the PHES plant and GT generate power. A constraint limiting the combined output of the PHES plant and GT plant is set based on the maximum generation capacity of the CAES plant. This approximation of the CAES plant configuration was used previously for other case studies [11], [40]. The details of the CAES plant used for this analysis are shown in Table IV and are assumed to represent the plant, which will be connected to the AII power system in 2020 .

At present, it is unclear which reserve categories the CAES plant will contribute toward for the AII system. Therefore, the CAES plant's reserve capabilities are based around the contributions in which the existing open-cycle GTs and PHES provide for generation and pumping in the AII system, respectively. The contribution of the CAES plant to generation and pumping reserve capabilities is assumed as 30 and $100 \mathrm{MW}$ for each reserve category (POR, SOR, TOR1, and TOR2), respectively.

\section{G. Cost Data}

Fuel prices are based on predictions for 2020 from two main sources [42], [43]. A carbon tax of $€ 30 / t \mathrm{CO}_{2}$ based on the European Union emissions trading scheme was applied to fossil fuel burning generators. This was a realistic figure based on the carbon taxes used for previous AII case studies, which ranged between $€ 15 / \mathrm{t}$ and $€ 45 / \mathrm{t} \mathrm{CO}_{2}$ [28], [42], [44]-[46]. Generator VOM costs were obtained from several sources [45] [47] and start costs were derived from historic start costs [27]. Cost data for the CAES plant were based on Thorner et al. [41]. All cost data were normalized to 2012 values using consumer price indices [48].

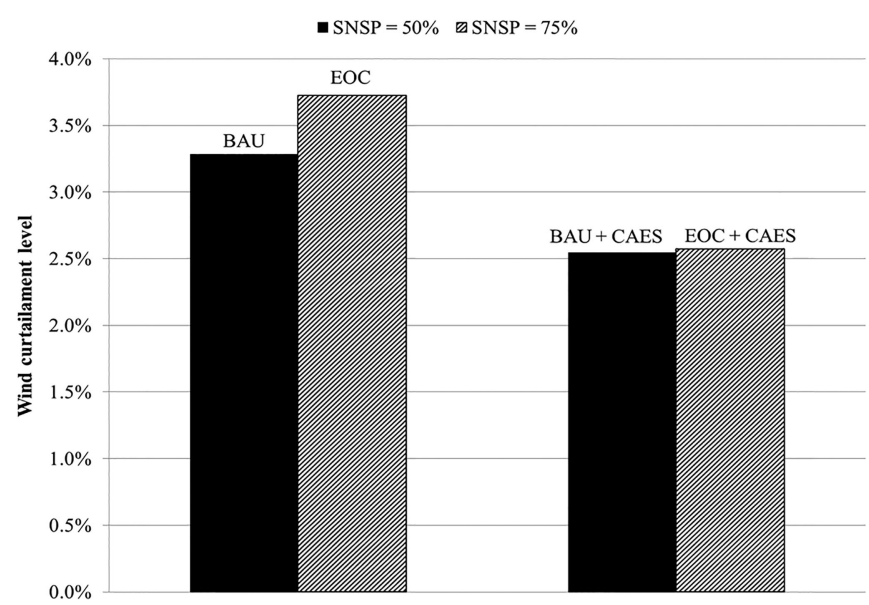

Fig. 2. System wide wind curtailment levels.

IV. RESUlts AND Discussion

A. System-Wide Wind Curtailment

The main result from this analysis is an estimate of the 505 system-wide wind curtailment levels in the 2020 AII system for 506 various scenarios including with and without CAES. The cur- 507 rent AII system can accommodate a maximum SNSP limit of 508 50\%; however, if mitigation measures are introduced, an oper- 509 ational limit of $75 \%$ SNSP is possible. The impact that this 510 increase has on the system for different scenarios is shown in 511 Fig. 2.

The wind curtailment levels are reduced due to the addition 513 of the CAES plant in the BAU + CAES and EOC + CAES. 514 The difference between the EOC and the EOC + CAES wind 515 curtailment levels are $1.2 \%$. For instance, when a curtailment 516 event occurs in the EOC + CAES scenario, for each $100 \mathrm{MW} 517$ of increased demand created by the CAES plant in compres- 518 sion mode, it allows $75 \mathrm{MW}$ of wind to remain connected 519 and increases the synchronous generation by $25 \mathrm{MW}$ to sat- 520 isfy the SNSP limit. Similarly, for the BAU + CAES scenario, 521 CAES allows $50 \mathrm{MW}$ of wind to remain connected to the AII 522 system.

\section{B. Economic Assessment}

A comparison of the wind generation revenue loss as a result 525 of wind curtailment is presented in Table V. The pool rev- 526 enue (product of price received in $€ / M W h$ and generation in 527 $\mathrm{MWh}$ ) is the revenue collected by each generator in the SEM. 528 Therefore, the revenue loss is a product of average annual price 529 received and the amount of wind curtailed for each scenario. $\quad 530$

The revenue loss decreases substantially as a result of 531 increasing the SNSP limit to 75\%. The addition of the CAES 532 plant further decreases the revenue loss and in turn increases 533 the revenue for wind generation by $€ 10$ million for the EOC +534 CAES scenario. Wind curtailment levels above 5\% have been 535 suggested to have significant economic risk for the long-term 536 growth of wind farm development in Ireland [35]. Moreover, 537 compensation payments for wind curtailment will cease on the 538 January 1, 2018. Therefore, the results suggest that increasing 539 


\begin{tabular}{|c|c|c|c|}
\hline Scenario & SNSP $(\%)$ & $\begin{array}{c}\text { Wind curtailment } \\
\text { level }(\%)\end{array}$ & $\begin{array}{c}\text { Revenue loss } \\
(€ \text { million })\end{array}$ \\
\hline BAU & 50 & 3.3 & 22 \\
\hline BAU+CAES & 50 & 2.5 & 17 \\
\hline EOC & 75 & 3.7 & 35 \\
\hline EOC+CAES & 75 & 2.6 & 25 \\
\hline
\end{tabular}

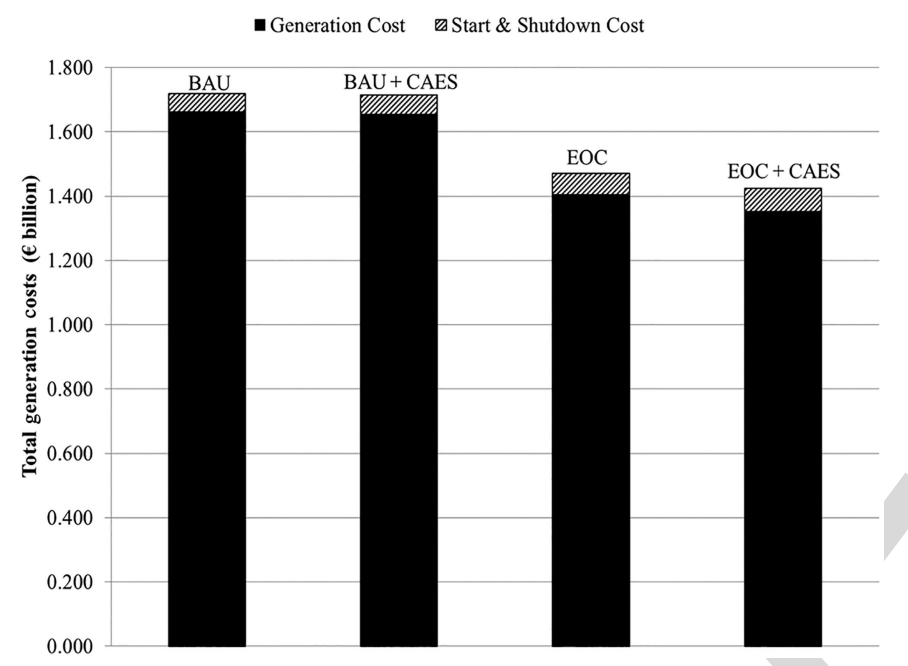

TABLE V

REVENUE LOSS COMPARISON

Fig. 3. Total generation costs for each scenario.

the SNSP limit to $75 \%$ and utilizing a CAES plant mitigates wind curtailment and reduces the economic risk.

Furthermore, due to the addition of the CAES plant, the pool revenues for most of the other generator types increased. This is mainly due to an increase in the average annual SMP from $€ 65 / \mathrm{MWh}$ to $€ 68.5 / \mathrm{MWh}$ for the EOC and EOC + CAES scenarios, respectively. This is beneficial for some of the generators as they are paid a higher price from the pool but this has a knock-on effect to the electricity consumer.

The overall economic benefit of moving from $50 \%$ to $75 \%$ SNSP limit and the inclusion of the CAES plant can be quantified by comparing the total generation costs for the AII system. Fig. 3 presents the total generation costs (including VOM cost, fuel cost, start and shutdown costs, and emissions costs) for each scenario over the year 2020 .

The higher SNSP limit and the inclusion of the CAES plant leads to lower total annual generation costs. The CAES plant's benefit to the system results in a reduction in costs of $3.3 \% \mathrm{com}$ pared to the EOC scenario. This equates to $€ 50$ million over the year 2020. This reduction cannot be attributed to a single event but occurs as minor cumulative changes over the year. From a technical perspective, this reduction is due to the CAES plant's ability to provide additional flexibility to the AII system.

Moreover, based on a capital cost of $€ 0.6$ million/MW for the CAES plant and annual savings of $€ 50$ million, the payback period is less than 4 years for the AII system. However, the payback period would differ for a private investor and a detailed cost-benefit analysis would determine whether it is a viable technology.

\section{CONCLUSION}

The economic benefits of CAES to wind generation were 570 evaluated using the power systems and market modeling soft- 571 ware PLEXOS. Based on the modeling conducted, it was 572 determined that a 270-MW CAES plant in conjunction with a 573 $75 \%$ SNSP limit can reduce wind curtailment levels to $2.6 \%$ in 574 2020.

It was also shown that the addition of CAES increases the 576 revenue for wind generation by $€ 10$ million for the EOC +577 CAES scenario. This is beneficial to the wind farm developers, 578 as it reduces their economic risk and encourages development. 579 Furthermore, CAES can contribute to the AII system other than 580 avoidance of wind curtailment. For instance, it can reduce total 581 annual generation costs by $3.3 \%$ relative to the proposed 2020582 EOC scenario. These benefits are external to a private financial 583 assessment of a CAES project but should be considered in an 584 overall cost-benefit analysis.

\section{ACKNOWLEDGMENT}

The authors would like to express their appreciation to 587 Energy Exemplar for providing an academic license for 588 PLEXOS and the technical support received. Furthermore, they 589 would also like to express their gratitude to Dr. P. Deane and 590 E. McGarrigle of the UCC Energy Policy and Modelling Group 591 for their guidance.

\section{REFERENCES}

[1] International Energy Agency, Technology Roadmap Wind Energy, 2013. 594

[2] European Parliament, Directive 2009/28/EC of the European Parliament 595 and of the Council of the European Union on the Promotion of the Use of 596 Energy From Renewable Sources. European Parliament, 2009, pp. 16-62. 597

[3] Department of Communications, Energy and Natural Resources, 598 "National Renewable Energy Action Plan," 2009.

[4] Eirgrid and SONI, "Ensuring a Secure, Reliable and Efficient Power System in a Changing Environment," 2011.

[5] Eirgrid and SONI, "All-Island Generation Capacity Statement 20122021," Dublin, Ireland, 2012.

[6] R. Mullen. (2011). Explores the Policy Challenges Ahead if Ireland is to 604 Meet its 2020 Targets [Online]. Available: http://www.mcdowellpurcell. 605 ie/content/curtailment-policy-challenge

[7] Eirgrid and SONI, 2011 Curtailment Report, Dublin, 2012.

[8] Commission for Energy Regulation, Treatment of Curtailment in Tie- 608 Break Situations, Dublin, 2013.

[9] T. Weiss, A. Wänn, P. Leahy, and E. V. Mc Garrigle, "Power system 610 overview and RES integration Ireland," 2013.

[10] A. Evans, V. Strezov, and T. J. Evans, "Assessment of utility energy stor- 612 age options for increased renewable energy penetration," Renew. Sustain. 613 Energy Rev., vol. 16, no. 6, pp. 4141-4147, Aug. 2012.

[11] A. Foley and I. Díaz Lobera, "Impacts of compressed air energy storage 615 plant on an electricity market with a large renewable energy portfolio," 616 Energy, vol. 57, pp. 85-94, Aug. 2013.

[12] R. Loisel, A. Mercier, C. Gatzen, N. Elms, and H. Petric, "Valuation 618 framework for large scale electricity storage in a case with wind curtail- 619 ment," Energy Policy, vol. 38, no. 11, pp. 7323-7337, Nov. 2010.

620

[13] D. J. Evans, D. M. Reay, N. J. Riley, W. I. Mitchell, and J. Busby, 621 "Appraisal of underground energy storage potential in Northern Ireland," 622 Keyworth, 2006.

[14] Gaelectric Energy Storage. (2011). Larne [Online]. Available: http:// 624 www.gaelectric.ie/index.php/energy-storage/larne/, accessed on May 3, 625 2013.

[15] Electric Power Research Institute-Department of Energy, Handbook of 627 Energy Storage for Transmission \& Distribution Applications. Palo Alto, 628 CA, USA: EPRI-DOE, 2003.

[16] J. Ilic et al., "Technical and economic analysis of various power generation resources coupled with CAES systems," USA, 2011. 
[17] I. Glendenning, "Long-term prospects for compressed air storage," Appl. Energy, vol. 2, no. 1, pp. 39-56, Jan. 1976.

[18] A. CAES. (2013). APEX CAES [Online]. Available: http://www.apexcaes. com, accessed on Oct. 31, 2013.

[19] Eirgrid and SONI, All-Island Generation Capacity Statement 2013-2022, Dublin, 2013.

[20] Sunday Business Post, Gaelectric to tap into EIB funds for plant, Dublin, Sep. 22, 2013

[21] RWE Power, "ADELE-Adiabatic compressed-air energy storage for electricity supply," 2011.

[22] T. Mcbride, A. Bell, and D. Kepshire, "ICAES innovation: Foam-based heat exchange," Seabrook, TX, USA, 2013.

[23] A. Foley, B. P. Ó Gallachóir, J. Hur, R. Baldick, and E. J. McKeogh, "A strategic review of electricity systems models," Energy, vol. 35, no. 12, pp. 4522-4530, Dec. 2010.

[24] Department of Communications, Energy and Natural Resources. (2008) All Island Electricity Grid Study [Online]. Available: http://www.dcenr. gov. ie/Energy/North-South+Co-operation+in+the+Energy+Sector/All+ Island+Electricity+Grid+Study.htm

[25] Energy Exemplar. (2013). PLEXOS ${ }^{\circledR}$ Integrated Energy Model [Online]. Available: http://www.energyexemplar.com/, accessed on Nov. 4, 2013.

[26] Eirgrid and SONI, "System services consultation finance arrangements," 2012.

[27] Commission for Energy Regulation, "Validation of market simulation software in SEM to end 2012," Dublin, Ireland, 2011.

[28] J. P. Deane, G. Dalton, and B. P. Ó Gallachóir, "Modelling the economic impacts of $500 \mathrm{MW}$ of wave power in Ireland," Energy Policy, vol. 45, pp. 614-627, Jun. 2012.

[29] E. V. Mc Garrigle, J. P. Deane, and P. G. Leahy, "How much wind energy will be curtailed on the 2020 Irish power system?," Renew. Energy, vol. 55, pp. 544-553, Jul. 2013.

[30] J. P. Deane, G. Drayton, and B. P. Ó Gallachóir, "The impact of subhourly modelling in power systems with significant levels of renewable generation," Appl. Energy, vol. 113, pp. 152-158, Jan. 2014.

[31] E. Denny, "The economics of tidal energy," Energy Policy, vol. 37, no. 5, pp. 1914-1924, May 2009

[32] NERA Economic Consulting, "Market simulation data \& model validation," New York, NY, USA, 2008.

[33] Eirgrid, "All Island TSO facilitation of renewables studies," Dublin, Ireland, 2010.

[34] Eirgrid, "Grid 25 A Strategy for the Development of Irelands Electricity Grid for a Sustainable and Competitive Future," 2010.

[35] Eirgrid, North-South $400 \mathrm{kV}$ Interconnection Development, Dublin, 2013.

[36] Eirgrid and SONI, Operational Constraints Update, Dublin, 2013.

[37] Commission for Energy Regulation, All Island Project Market Simulation Model Validation, Dublin, Ireland, 2007.

[38] Sustainable Energy Authority of Ireland, Operating Reserve Requirements as Wind Power Penetration Increases in the Irish Electricity System, Dublin, Ireland, 2004.

[39] J. P. Deane, "Improved modelling of pumped hydro energy storage," University College Cork, Cork, Ireland, 2012.

[40] M. Ni, Z. Zhou, and D. Osbo, "Economic and operation benefits of energy storage-a case study at MISO," in Proc. IEEE Power Energy Soc. Gen. Meeting, 2012, pp. 1-7.

[41] T. Thorner et al., "The economic impact of CAES on wind in TX, OK, and NM," Houston, 2005.

[42] P. Grant and E. Phillips, "The impact of wind on pricing within the single electricity market," London, Feb. 2011.

[43] Eirgrid, "Executive Summary: Interconnection economic feasibility report," Dublin, Nov. 2009.

[44] A. Tuohy and M. O'Malley, "Pumped storage in systems with very high wind penetration," Energy Policy, vol. 39, no. 4, pp. 1965-1974, Apr. 2011.

[45] R. Doherty, H. Outhred, M. O. Malley, and S. Member, "Establishing the role that wind generation may have in future generation portfolios," vol. 21, no. 3, pp. 1415-1422, 2006.

[46] D. Connolly, H. Lund, B. V. Mathiesen, and M. Leahy, "Modelling the existing Irish energy-system to identify future energy costs and the maximum wind penetration feasible," Energy, vol. 35, no. 5, pp. 2164-2173, May 2010.

[47] Mott MacDonald, UK Electricity Generation Costs Update, Brighton, England, 2010

[48] Central Statisitics Office. (2013). Annual Percentage Change of Consumer Price Index [Online]. Available: http://www.cso.ie/quicktables/ GetQuickTables.aspx ?FileName $=$ CPA01C3.asp $\&$ TableName $=$ Annual + Percentage + Change $\&$ StatisticalProduct=DB_CP

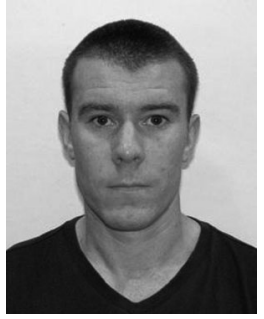

Brendan Cleary (S'13) received the B.A. and B.A.I. 709 degrees in civil engineering and the M.Sc. degree 710 in civil engineering from Trinity College Dublin, 711 Dublin, Ireland, in 2006 and 2011, respectively. He is 712 currently pursuing the Ph.D. degree at Dublin Energy 713 Laboratory, Dublin Institute of Technology, Dublin, 714 Ireland.

His research interests are in wind generation inte- 716 gration, energy policy and economics. $\quad 717$

Mr. Cleary is a Chartered Engineer of Engineers 718 Ireland. He received the Fiosraigh Dean of Graduate 719 Research School and Fulbright-Enterprise Ireland Awards in 2011 and 2013, 720 respectively.

721

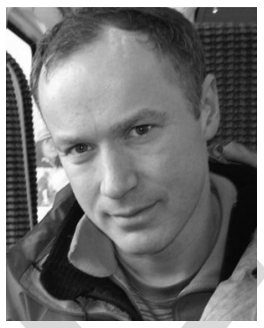

Aidan Duffy received the B.A. and B.A.I. degrees 722 in civil engineering, and the Ph.D. degree in build- 723 ing material's durability from Trinity College Dublin, 724 Dublin, Ireland, in 1990 and 1995, respectively. $\quad 725$

$\mathrm{He}$ is a Professor with the School of Civil 726 Engineering, Dublin Institute of Technology, Dublin, 727 Ireland, and is also the Centre Manager with Dublin 728 Energy Laboratory, Dublin, Ireland. His research inter- 729 ests include numerical modeling of energy systems, 730 energy policy, life cycle economic and environmental 731 assessment of built structures, and energy systems. $\quad 732$ Dr. Duffy is a Chartered Engineer of Engineers Ireland.

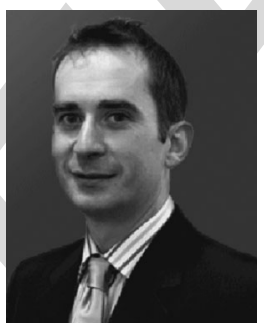

Alan O'Connor received the B.A. and B.A.I. degrees 734 in civil engineering, and the Ph.D. degree in proba- 735 bilistic analysis from Trinity College Dublin, Dublin, 736 Ireland, in 1994 and 2001, respectively. 737

$\mathrm{He}$ is an Associate Professor with the Department 738 of Civil Engineering, Trinity College Dublin, Dublin, 739 Ireland. He has extensive national and international 740 experience in infrastructural risk analysis and proba- 741 bilistic safety assessment.

Dr. O'Connor is a Chartered Engineer and Fellow 743 of Engineers Ireland.

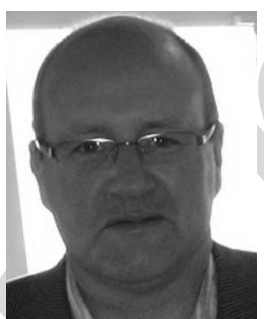

Michael Conlon (M'88) received the Dip.E.E. and 745 B.Sc. degrees from Dublin Institute of Technology, 746 Dublin, Ireland, in 1982, and the M.Eng.Sc. and 747 Ph.D. degrees from the University College, Galway, 748 Ireland, in 1984 and 1987, respectively, all in electri- 749 cal engineering. $\quad 750$

$\mathrm{He}$ is the Head of the Department of Control 751 Engineering with Dublin Institute of Technology, 752 Dublin, Ireland. His research interests include power 753 systems analysis and control applications, power sys- 754 tems economics, integration of wind energy in power 755 networks, and quality of supply and reliability assessment.

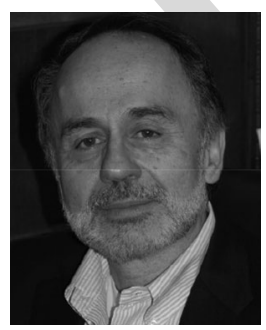

Vasilis Fthenakis received the B.S. degree in chem- 757 istry from University of Athens, Athens, Greece, in 758 1975, the MS degree in chemical engineering from 759 Columbia University, New York, NY, USA, in 1978, 760 and the Ph.D. degree from New York University, New 761 York, NY, USA, in 1991

$\mathrm{He}$ is a Senior Chemical Engineer and the 763 Head of the Photovoltaics Environmental Research 764 Center, Brookhaven National Laboratory, New York, 765 NY, USA, in a joint appointment with Columbia 766 University, New York, NY, USA, where he is a 767 Professor with the Department of Earth and Environmental Engineering and 768 the Founder and Director of the Center for Life Cycle Analysis.

Dr. Fthenakis is a Fellow of the American Institute of Chemical Engineers 770 and a Fellow of the International Energy Foundation.

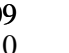

2

4

,

.

